\title{
OSTEOGENESIS IMPERFECTA
}

\author{
BY \\ J. G. A. DAVEL, T. FICHARDT and D. VAN DER SPUY \\ From the Department of Radiology, Pretoria Hospital and University, South Africa
}

(RECEIVED FOR PUBLICATION JUNE 7, 1956)

Osteogenesis imperfecta is a disease of infancy and childhood, but it has been observed in all age groups. It is characterized by increased fragility of the bones, which fracture on minor trauma, resulting in severe or lesser degrees of crippling. The eyes may be prominent and the sclerotics blue. The neck is usually short, the thorax misshapen, the vertebral column angulated, and the limbs bent.

In the severe form of the disease fracture deformities may occur in utero or the bones may break during parturition. Many of these cases of osteogenesis imperfecta congenitalis are stillborn or succumb shortly after birth.

In the less severe form, osteogenesis imperfecta tarda, the baby is apparently normal at birth, and only after the lapse of several years are multiple fractures encountered; this tendency to fracture disappears at puberty. Fairbank (1951) describes a case of a young girl with striking blue sclerotics who sustained the first of many fractures at the age of 7 .

Most patients die young, but a few survive for many years despite the severity of the disorder. Fairbank notes two cases. One, a boy, a prenatal case, was alive at the age of 19 , though bedridden since birth. The other, a girl, also a prenatal case, only slightly less severe and markedly deformed, is still able to earn a living as a secretary at the age of 29 .

Lawford Knaggs (1924) cites a patient with multiple fractures at birth, who evidently earned his living even though a cripple for many years, but who in later years was poverty stricken, and as a result of hunger malacia died from multiple fractures at the ripe old age of 68 .

Brailsford (1953) states that the plasticity of the bones during infancy and adolescence, which causes the pronounced curvatures and deformities, appears to consolidate in early adult life. There is little or no progress in the deformity in later life.

\section{Aetiology and Pathology}

The aetiology is unknown; there is, however, a hereditary trait. Fairbank states that hereditary and familial influences play a part in the minority of prenatal and post-natal cases, the disease being transmitted by either parent. Family trees have been recorded covering four generations but not all the individuals in the family have been equally affected. Blue sclerotics have been present in some, otosclerosis in others, while in yet others there were multiple fractures in the absence of blue sclerotics or otosclerosis. Roger (1936) states that $60 \%$ of the cases with blue sclerotics tend to develop otosclerosis.

Bickel, Ghormley and Camp (1943) reviewed 40 cases at the Mayo Clinic and reported that blue sclerotics were consistently associated with the hereditary type but not with the non-hereditary type. In their series $27.5 \%$ were hereditary and $72.5 \%$ had no known family history of the disease. They found deafness in $45.5 \%$ of the hereditary type and only $17 \cdot 3 \%$ in the non-hereditary cases. The family tree may thus reveal fiail joints and recurrent dislocations in one member, deafness and otosclerosis in another and blue sclerotics or cutis laxa in a third. Considered thus, this departure from the normal is attributable to mesencyhmal dysplasia hereditarily dominant.

Osteogenesis imperfecta is a systemic disease of the mesenchymal tissues of the body, thus some tissues derived from the mesenchyme (sclera, ligaments, bone supporting tissue) are inferior and exhibit the characteristic stigmata. Other mesenchymal tissues, however, appear normal.

The skin of patients suffering from osteogenesis imperfecta is thin and of a fine texture, occasionally with atrophic blotches. Bauer (1920) found a systemic defect in the development of connective tissues with a greater variety of cell forms than is normally encountered. The differences are more pronounced in the more specialized tissues.

Follis (1952) by his histiogenetic examinations corroborates this finding: reticulum spindles are not properly converted into collagen fibres. Biering and Inversen (1955) describe a case of osteogenesis imperfecta with an accompanying Ehlers-Danlos syndrome.

No hormonal deficiency has been cited as a causal factor. 
On pathological examination it has been determined that the cortex is thin as a result of the impaired periosteal bone formation, diminished osteoblastic activity and diminished calcium deposition, because the collagen matrix is defective. The result is incomplete ossification, soft and fragile bones which bow and fracture. After fractures, adequate callus is formed but not replaced by strong bone so that fractures can ensue at these same sites.

The thin sclerotics allow the underlying pigment to become visible. Deafness, usually in the third decade, is a result of otosclerosis or labyrinthine disturbances.

The ligaments are lax and the muscles hypotonic. This can result in bowing and multiple fractures of the long bones and ribs, compression of vertebrae, a triradiate pelvis and temporal bulging of the skull which in some cases sags on to the cervical vertebrae like a 'tam-o'-shanter'. Thus eventually a severe dwarf-like deformity ensues.

The number of fractures encountered in individual cases is variable. Fairbank (1951) states that in severe cases the fractures are spontaneous and relatively painless. In newborn babies, as many as a hundred fractures may be present, mostly of the ribs. He describes a patient with deep blue sclerotics who died at the age of 8 years, after sustaining 98 fractures.

In one of our cases the patient was apparently perfectly normal in appearance until at the age of 4 years the vertebrae collapsed and he developed a curved spine and bent legs. Previously he could play with other children freely. Recently he injured the thorax and radiological examination revealed three fractured ribs - the left ninth, tenth and eleventh ribs; only these six fractures were encountered in the skeletal survey and they revealed union with ample callus. This case is typical of osteogenesis imperfecta tarda.

Von Lobstein (1833) was evidently the first person to describe the post-natal group under the designation of osteopsathyrosis idiopathica. Vrolik (1849) coined the term osteogenesis imperfecta to describe the ante-natal group.

In view of the fact that osteogenesis imperfecta is encountered at all ages, Brailsford (1943) recommends that terms like 'osteopsathyrosis idiopathica; 'fragilitas ossium' and 'hereditary fragility of bone' and many similar designations merely refer to various examples of the same dystrophy and should be discarded in favour of the all-embracing term of osteogenesis imperfecta. He regards Vrolik's osteogenesis imperfecta, or the ante-natal form as the most severe example, whilst the less severe types are encountered post-natally. Osteogenesis imper- fecta has now been universally recognized as the most acceptable term for this dystrophy.

\section{Classification}

Osteogenesis imperfecta is the all embracing term used today to include the foetal, infantile, adolescent and adult examples of the disease. Although osteogenesis imperfecta is a general bone disease that is present from birth, the clinical and radiological features seem to differ quite prominently in the various age groups. It therefore seems feasible, for the sake of clarity, to divide osteogenesis imperfecta into four age groups, as suggested by Vernon Luck (1950), but admitting that there is no very clear cut division between these age groups.

The classification we suggest is as follows:

(1) Osteogenesis Imperfecta Congenitalis. The condition can be recognized in utero. These cases are usually stillborn and represent the most extreme examples of the disease, which is characterized by multiple fractures and deformities. At birth the skull is usually collapsed for it possesses little ossification and cannot stand up to the strain of parturition. Knaggs describes such a skull as a "membranous bag of bones".

Fairbank describes these cases as the prenatal thick bone type, and says that these are the severe cases born with limbs that are stunted as in achondroplasia and with numerous fractures, notably in the ribs. The major long bones are thick, blunt and stunted. They have a crumpled up appearance due to one or more fractures, which apparently do not perforate the periosteum and which are associated with ample callus. These typical radiological changes are seen at birth or up to three months after birth if the baby survives as long as that.

(2) Osteogenesis Imperfecta Infantis. This type represents a less severe degree of skeletal deficiency. These cases usually live from one to eight years, during which time they sustain innumerable fractures, following even the mildest trauma, from which they eventually succumb.

Fairbank describes these cases as the slender fragile bone type, and says the condition is seen in prenatal cases which survive more than a few months, and in all post-natal cases. The skeleton as a whole is osteoporotic and the long bones are soft, fragile and slender. The cortex is practically absent; the epiphyseal extremities are by contrast abnormally large, and are sometimes honeycombed. Transverse lines of dense bone, straight or wavy, often mark the ends of the metaphysis. The skull is usually extremely thin, and the petrous bones by contrast 
excessively dense. The soft skull sags over the cervical spine in 'tam-o'-shanter' style. There is extreme compression of the soft and osteoporotic vertebrae which exhibit biconcave articular surfaces. The soft pelvis becomes triradiate due to compression. Deformities due to fracture or bending of the long bones are common. The ribs are especially prone to multiple fractures causing deformity of the thorax. These patients end up as miserably deformed dwarfs.

(3) Osteogenesis Imperfecta Tarda. In these cases there is usually far more substantial ossification of the skeleton at birth than in the foetal and infantile types, in fact, some of these patients pass through an uneventful infancy and early childhood before they begin their careers of multiple fractures. A delay of the first fracture until after the age of 5 years is generally recognized as representing a case of osteogenesis imperfecta tarda.

Fairbank (1935) was the first to suggest the name of osteogenesis imperfecta cystica for an exceedingly rare example of the disease. Only three cases have been recorded, all by Fairbank. During the first few years of life the limbs may show no more than osteoporosis, though the condition dates from birth. Cystic changes which are more pronounced in the lower than in the upper limbs become increasingly evident with advancing years. Deformity due to fracture and bending of bone is progressive, and with advancing years all the bones of the body, including the skull, show marked cystic changes. Fairbank had occasion to follow one of these cases from the age of 5 until she died at the age of 23 . Honeycombing was distributed throughout the whole skeleton, becoming more evident with age.

Brailsford (1943) reported four cases of a condition suggesting scurvy, subperiosteal haemorrhages being more frequent than fractures occurring as a complication of osteogenesis imperfecta. This was followed by a paper by Baker (1946) on 'Hyperplastic Callus Simulating Sarcoma in Two Cases of Fragilitas Ossium'. Fairbank and Baker (1948) published details of eight cases of osteogenesis imperfecta that developed hyperplastic callus formation. The bones affected were one or both femora in every case, the humerus in four cases, and the radius and ulna less frequently. Both sexes are affected, and the age at which it occurs is usually from 1 to 15 years. Fairbank states that the cause of the curious features found in these cases is obscure. He says that Brailsford's suggestion of scurvy playing a part is contradicted by the fact that Baker failed to find the faintest sign of haemorrhage, old or recent, in his sections and there was strong evidence against lack of vitamin $C$ in these cases.

(4) Osteogenesis Imperfecta Adulta. This condition, although rare, occurs and must be included to round off the classification. These cases include all cases that appear to have recovered from the condition during infancy and adolescence, only to develop skeletal fragility again in adult life. The case described by Lawford Knaggs and cited in this article is a good example of osteogenesis imperfecta adulta.

\section{Case Reports}

Case 1. John, a 5-year-old Bantu boy, is an example of osteogenesis imperfecta tarda. He was admitted to the Pretoria Hospital for investigation. During the course of the previous year his legs became gradually weaker and at present he is unable to walk and is a crippled dwarf.

His mother avers that he had been quite well at birth and had played normally with other children until a year ago. She then noticed that his back and right leg became bowed. Recently he hurt himself and complained of pain in the left side of the chest : this is slightly better now.

There were eight children in the family, two died at a tender age (probably measles in the one case and an accident in the other). The father is an epileptic and does not work. The mother is the breadwinner; she takes in washing and cares for the children.

The other five children are well and normal. John had measles as a baby and was vaccinated against smallpox. There were no maternal pre-natal complications, and his birth was normal. He was breast fed for three years and mealie porridge subsequently formed his main diet.

On examination he was an obvious crippled dwarf as the photograph illustrates (Fig. 1). He has blue sclerotics. He is poorly nourished. There are no tender areas. The skin covering the elbows is loosely attached, thickened and hyperpigmented. Most of the long bones are bowed to a variable extent. The head has descended on to the neck creating the impression of a short thick neck. There is a striking kyphosis of the thoraco-lumbar area with a barrel-shaped chest and atrophy of the trunk muscles. There is also atrophy of the limb muscles, especially of the lower extremities. The joints appear normal and there is no abnormality of the heart, lungs, or abdomen.

A blood Kolmer test was negative and the sedimentation rate normal.

A blood count gave: Haemoglobin $10 \cdot 3 \mathrm{~g}$. per $100 \mathrm{ml}$. $\left(71^{\circ}\right)$; R.B.C.s, 4,290,000, W.B.C.s, 6,000 (polymorphs $45^{\circ}$, lymphocytes $50^{\circ}$, monocytes $4 \%$, eosinophils $1^{\circ} \mathrm{o}$ ). Platelets were normal. The blood calcium level was $10.2 \mathrm{mg}$. $\%$, phosphorus $3.8 \mathrm{mg} .{ }^{\circ}$, alkaline phosphatase $15.5 \mathrm{~K}$.-A. units. Urine was negative for albumin and no red or white cells were seen. The glycien, alanine and methyl histidine excretion was normal. 
Radiological Signs. The following were of importance:

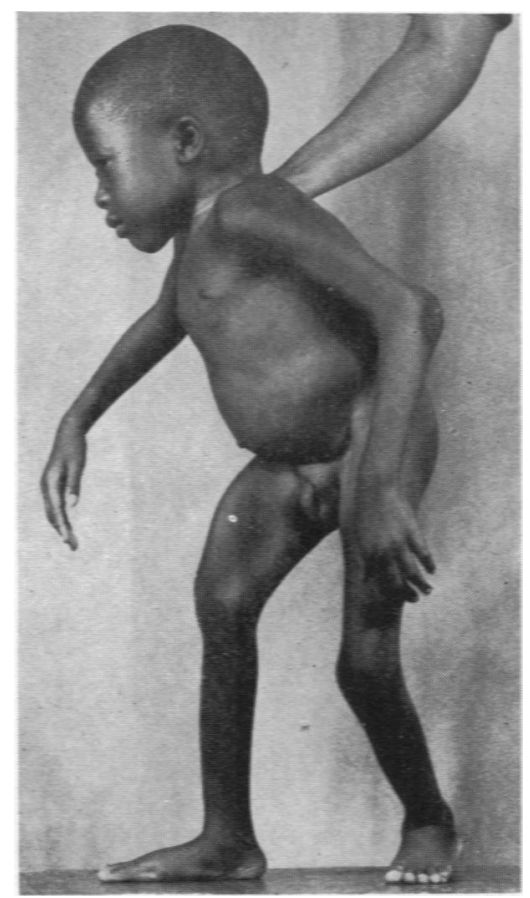

Fig. 1.-Bantu boy age 5 .

Skull. The skull is thinner than average (Fig. 2), the parietal areas bulge laterally and the base is definitely descended on to the upper cervical vertebrae (Fig. 3). The petrous bone is elevated on the left side. The sutures, fontanelles and sella turcica are within normal limits. The facial bones are small in relation to the vault.

Spine. There is a kypho-scoliosis of the upper spine (dorsal and proximal lumbar vertebrae) with obvious general osteoporosis and flattened deformity of all the vertebrae in the thoraco-lumbal veitebral column; wedge-shaped vertebrae especially, (Fig. 4), as well as a few biconcave and symmetrically flattened vertebral bodies (vertebra plana), are present.

Pelvis. Gross asymmetry and distortion, with the formation of a triadiate pelvis, are present with definite osteoporosis (Fig. 5).

Thorax. There is a slight degree of distortion and asymmetry with rib fractures exhibiting marked callus formation (Fig. 6). There are fractures of the right second and ninth ribs (anteriorly) and the seventh rib (posteriorly) as well as the left ninth, tenth and eleventh ribs (posteriorly).

Long Bones. Generalized osteoporosis with thin cortex and poor trabeculae is seen. The femora, tibiae and humeri are thinner than normal while the fore-arm bones are considered to be within normal limits.
The right femur is acutely curved anteriorly and the left tibia and fibula so to a lesser degree.

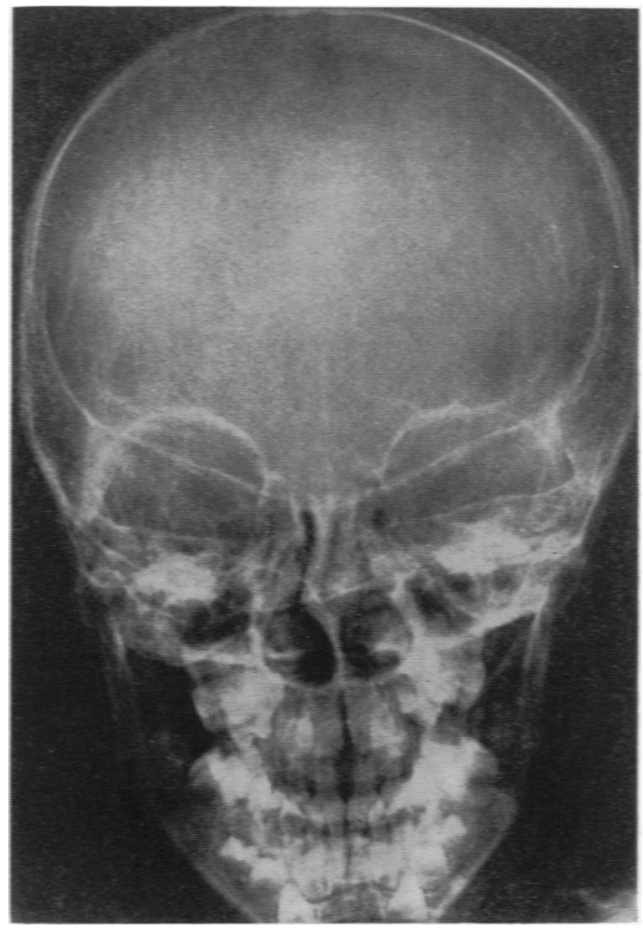

Fig. 2.-Pencil outline of skull.

Looser zones are observed in the proximal humeral shafts, right femur, proximal left tibia as well as in both olecranon processes. There are cystic areas in the proximal right femur indicative of defectively formed bones.

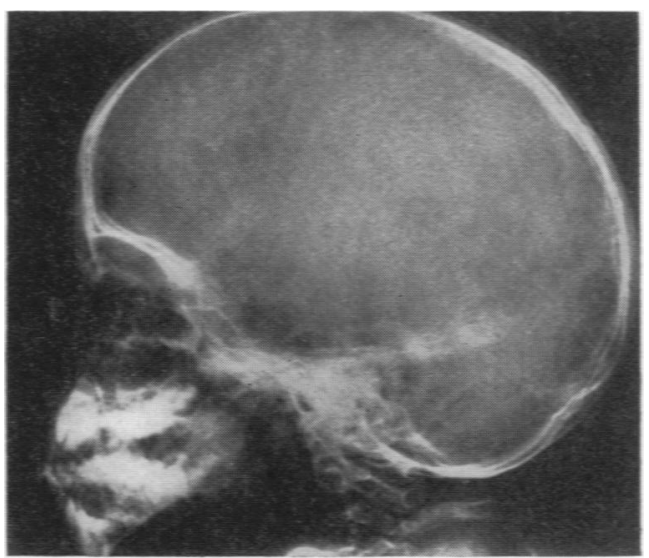

FiG. 3.-Sageing of the base of the skull over the cervical vertebrae and shortening of the neck. 


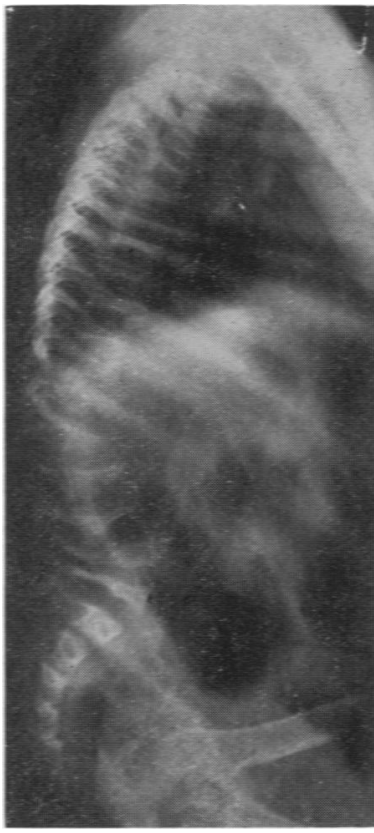

Fig. 4.-Typical biconcave wedgeshaped and flattened osteoporotic vertebrac.

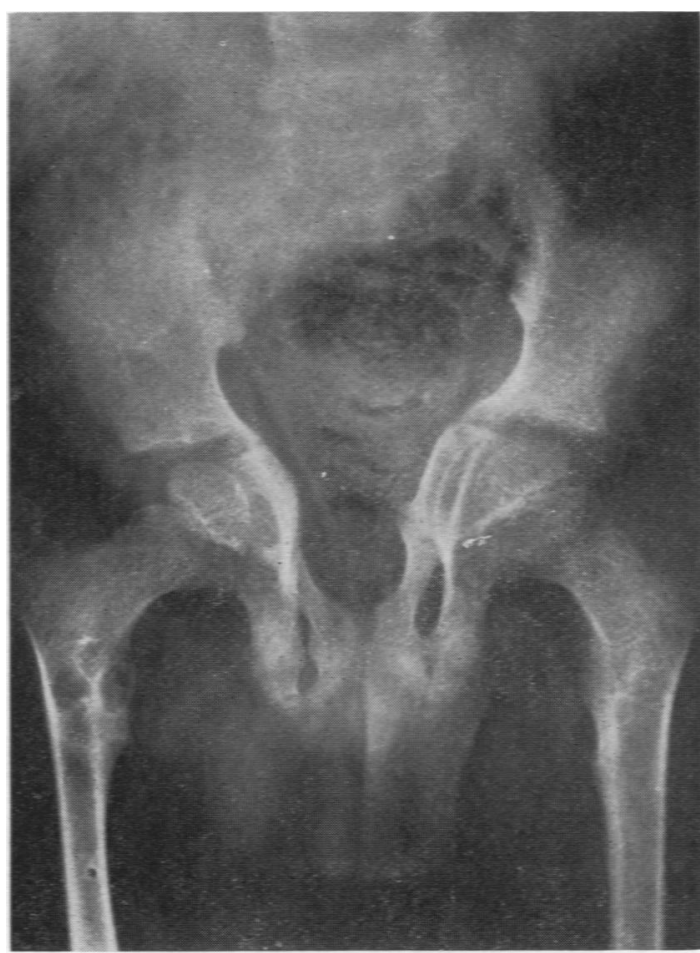

Fig. 5.-The typical triradiate pelvis, and cystic changes in the region of the lesser trochanter on the right side.

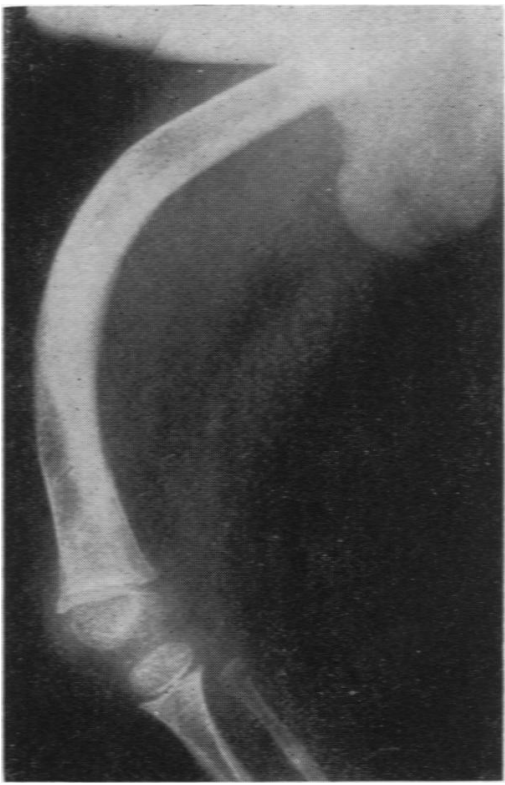

Fyc. 7.-Typical bowing of the right femur.

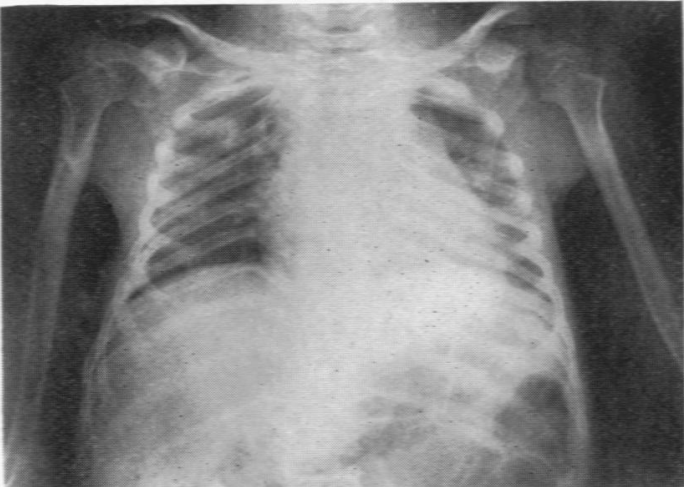

Fig. 6.- Note rib fractures. Spina bifida of T.1, T.2 and T.3. Looser zones present in both upper humeri. 
Another striking feature is the relatively widened ends of the femora, humeri and tibiae (proximally in the latter).

Transverse lines of arrested growth are present in the long bones. especially marked in the distal portions of the humeri.

The clinical and radiological features of this case reveal it as an example of osteogenesis imperfecta tarda, because (1) there are no clinical or laboratory findings indicating any other osteoporotic condition. (2) There were no deformities at birth and the child played normally with other children until 4 years of age. (3) Fractures occurred comparatively late. The few are recent but most of the vertebrae are flattened. (4) The long bones are relatively well developed.

Case 2. E.S. is a European boy aged 3 years and is an example of osteogenesis imperfecta infantis of the post-natal thin bone type. He was a breech delivery, the head being delivered with forceps (weight $5 \mathrm{lb} .10 \mathrm{oz}$ ) There is no mention of any fractures sustained during delivery. At the age of 2 months both upper arms fractured. No details are available. Two weeks later a fractured femur is recorded and $x$-ray examination at this stage revealed a uniting fracture of the other femur as well.

Apart from recurrent colds, sometimes accompanied by lung infections, E.S. was free from any illness.

His physical development was retarded; at 4 months he lifted his head, at 6 months he sat up. He has only

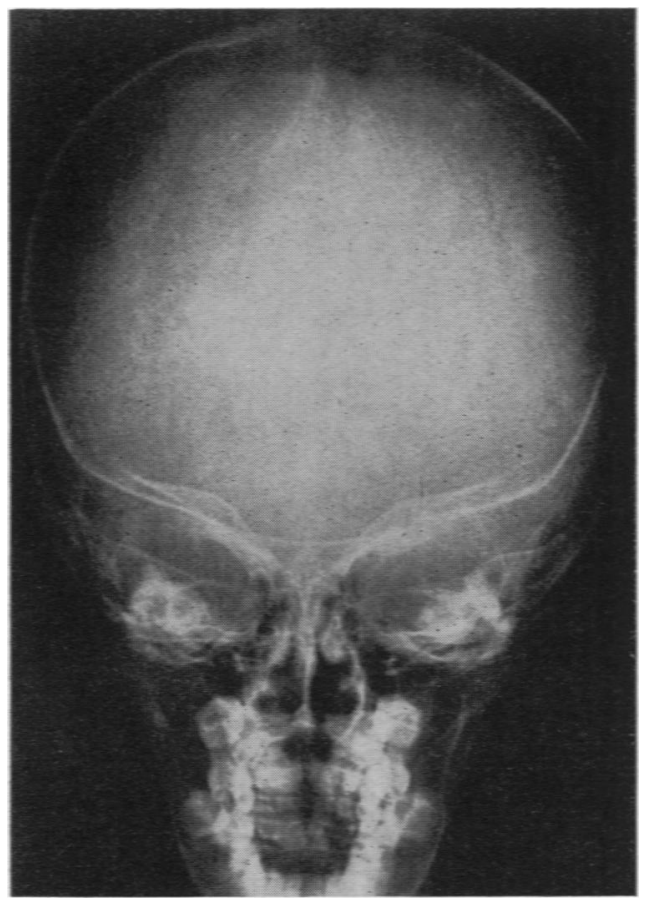

Fig. 8.-Pencil outline of skull bones.

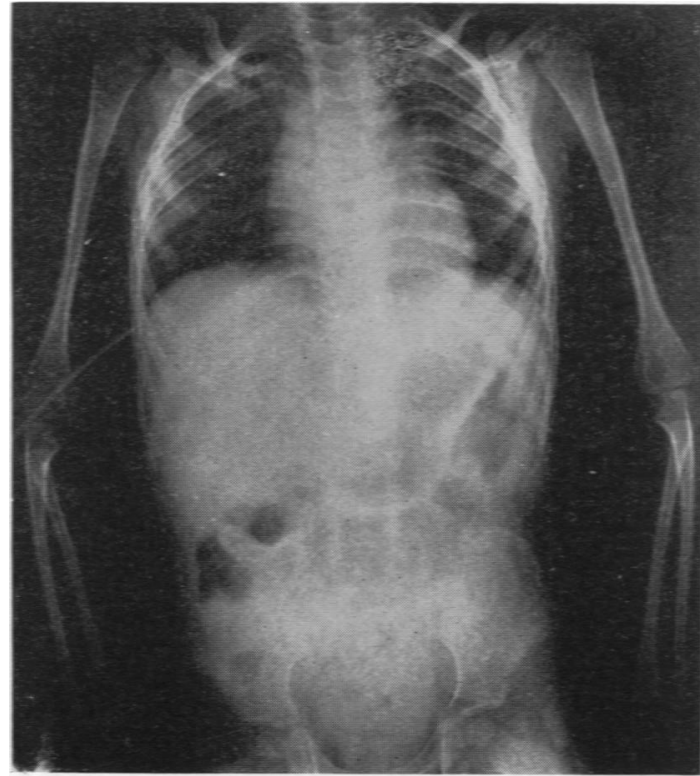

Fig. 9.-Slightly curved slender bones of the upper extremities.

been crawling for two months and with aid has been able to stand up for the last month. He speaks well, however, and appears to have normal intelligence.

On examination he is found to be a frail little boy with a large round head and carious teeth. He has deep blue sclerotics, a depressed thoracic wall, long thin arms and legs with excessively mobile joints as a result of lax ligaments. Blood examination showed that the levels of calcium and phosphorus are normal.

Radological Findings. The skull bones are extremely thin and the skull is somewhat sagged upon the cervical spine (Fig. 8). The vertebrae are osteoporotic and somewhat biconcave but not compressed. The pelvis is normal. The limb bones are long and slender with narrow shafts and bossed epiphyses (Figs. 9 and 10). There is evidence of multiple united rib fractures, and fractures of the shafts of the long bones, which have united or are in the process of uniting. There is surprisingly little bowing and deformity of the long bones, vertebral column or thoracic cage in this case, but nevertheless it is radiologically a typical example of osteogenesis imperfecta infantis of the post-natal thin bone type.

Case 3. S.G. is a European boy aged 6 years and is another example of osteogenesis imperfecta infantis of the post-natal thin bone type.

He was admitted to the Pretoria Hospital with pneumonia on October 16, 1955. He had a tendency to recurrent colds and had a continual dry cough since drinking paraffin at the age of 19 months. He had sustained fractures on five occasions. At the age of 18 months, in 1951, he had fallen from a bed $2 \frac{1}{2} \mathrm{ft}$. high and sustained a fracture of the lower humerus. There 

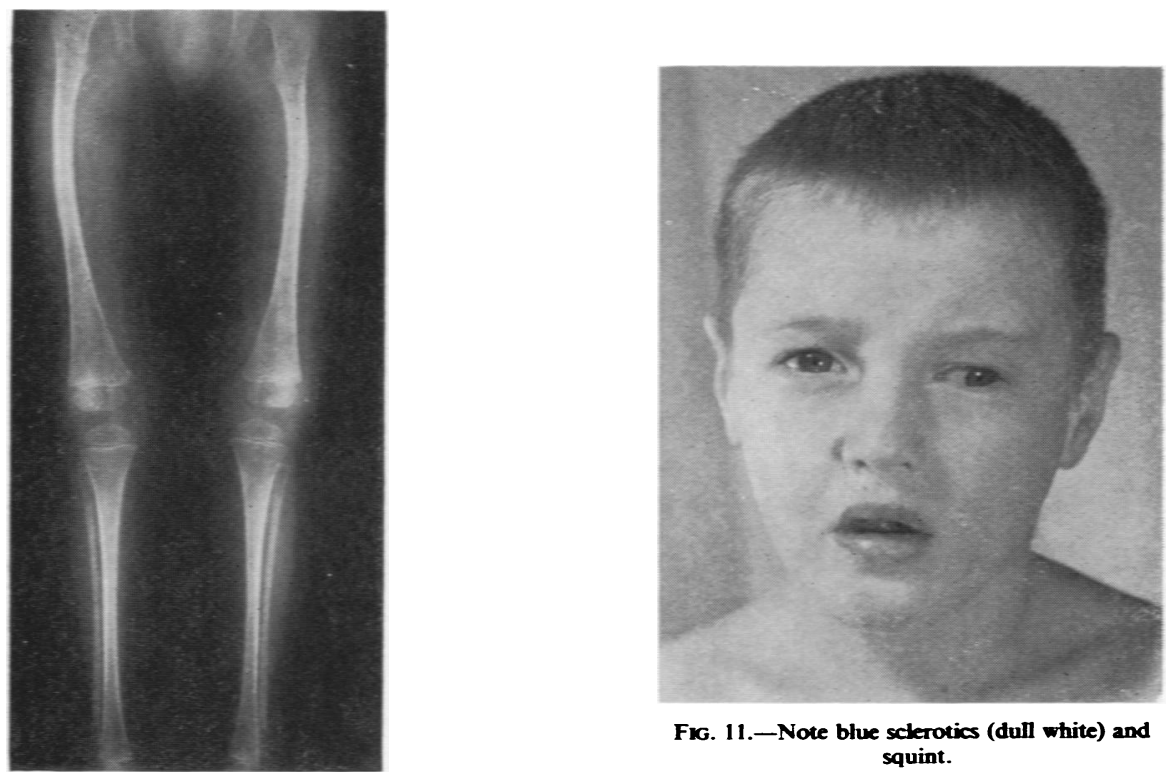

Fig. 11.-Note blue sclerotics (dull white) and squint.

Fig. 10.- Slightly curved stender bones of the lower extremities.

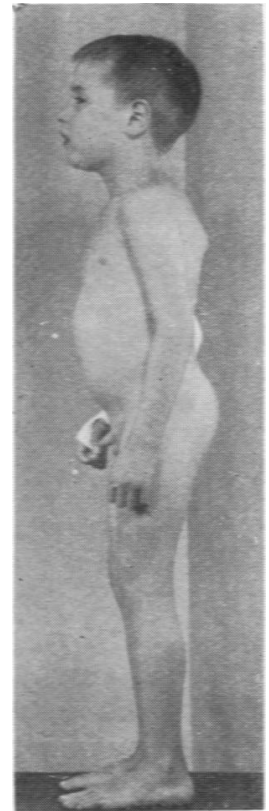

Fig. 12-Note shortening of nock and spine. Arm in plaster, after recent supracondylar fracture.

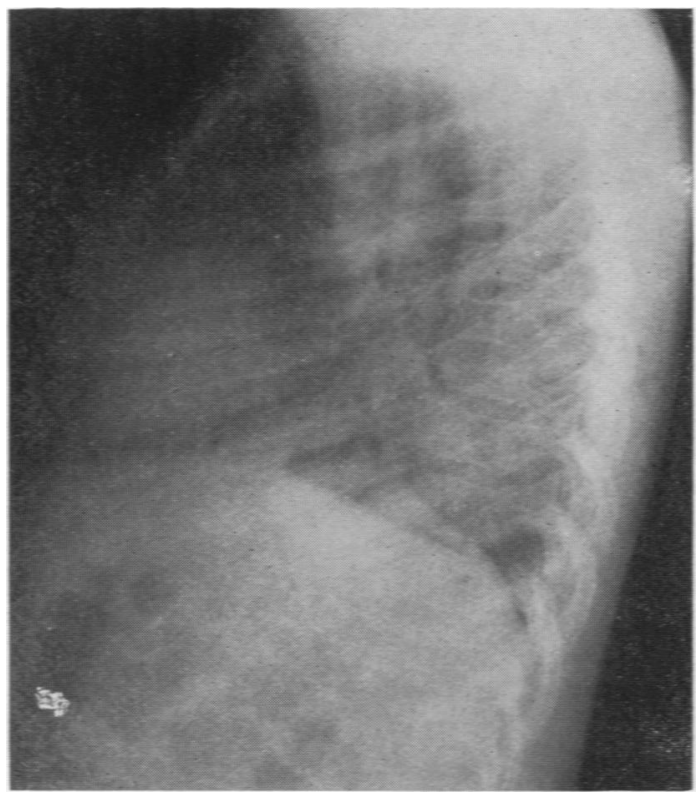

Fig. 13. - Osteoporosis of the vertebral bodies resulting in biconcave rather wedgeshaped thoracic vertebrae.

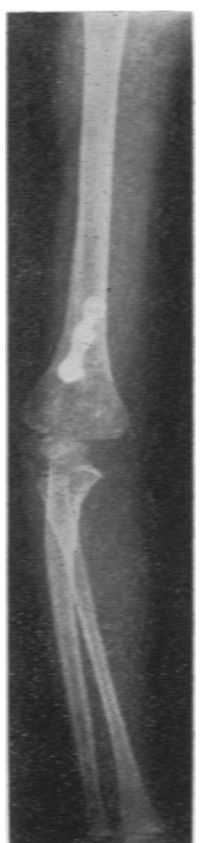

Fig. 14.-Phated supracondylar fracture. Note slender osteoporotic bones. 
was malunion with external rotation and angulation of the distal fragment. In May, 1952, he refractured the right humerus at the same site as the result of a fall. Again there was malunion. In June, 1952, after falling, or slipping on a cement ffoor, he fractured the left tibia. Yet again he fractured his arm in October, 1952. In January, 1953, he was subjected to an operation for the correction of the shortening and external rotation.

On October 31, 1955, while in hospital for pneumonia he slipped on the stoep and fell, fracturing the right radius and ulna. The arm is still immobilized in plaster of paris.

According to his mother the trivial trauma causing his fractures would not have affected normal children.

After the lipoid pneumonitis in 1951 he developed a superior strabismus on the left side; an unsuccessful operation for correction of the squint was undertaken in November, 1954. His eye now deviates to the lateral and inferior side. He has no hearing defects.

Initially his physical growth was impeded by feeding troubles; at the age of 14 months he started walking and his intelligence is within normal limits.

Family History. The father had no tendency to fractures, no deafness but has cardiomegaly.

The mother is aged 33 years and has a marked tendency to sustain fractures as a result of minor traumata. The first fracture occurred at the age of 7 years and the last in December, 1952. Since the age of 15 years she has been deaf in the right ear and this has steadily got worse.

Two other children, a daughter aged 3 and a son 5 months old, have, despite major injuries, never sustained fractures.

The father's family exhibit no tendency to sustain fractures or become deaf. The mother's father was deaf in the left ear, but never sustained fractures; her mother easily fractured her bones. Of the mother's five brothers and four sisters, all, except one brother and one sister, had sustained more than one fracture.

ANTE-natal History. S.G. was the first born and the mother had toxaemia from the sixth month and developed eclampsia at term. Labour was induced by rupture of the membranes and repeated injections. The delivery was normal and the baby cried lustily at birth. She remained well during the next two pregnancies.

EXAMINATION. On examination the patient was seen to be a young European boy, of fair nutritional state, but undersized for his age, with no anaemia, jaundice or cyanosis. He has blue sclerotics; pupil reflexes and fundi are normal. His left eye deviates externally and inferiorly and there is limitation of movement internally and superiorly. Lobar pneumonia (left base) had responded fully and rapidly to antibiotics.

The sedimentation rate was $4 \mathrm{~mm}$. in the first hour
(Westergren). The urine was negative for albumin; but microscopically pus cells, 1 r.b.c. per H.P.F., were seen.

A Mantoux test was negative (P.P.D. intermediate and second strength).

A blood count gave Hb $139 / 100$ ml., W.B.C. 34,000 (staff cells $14 \%$, polymorphs $65 \%$, lymphocytes $15 \%$, monocytes $6 \%$ ). Blood platelets were normal.

The blood calcium level was $11.8 \mathrm{mg} . \%$, phosphorus $1.7 \mathrm{mg} . \%$, alkaline phosphatase $17.5 \mathrm{~K} . \mathrm{A}$. units. On repetition after this report was known blood calcium $10.7 \mathrm{mg}$. phosphorus $3.6 \mathrm{mg}$. \%, alkaline phosphatase $16 \mathrm{~K}$.A. units. In a 24 -hour volume of urine $615 \mathrm{ml}$. cakcium was excreted and $144.4 \mathrm{mg}$. per 24 hours.

Radological Findings. The skull bones are thin, and the skull sits on the cervical spine in 'tam-o'-shanter' style giving the appearance of a short neck (Fig. 12). The upper thoracic vertebrae show the typical osteoporotic appearance with biconcave compression of the vertebral bodies resulting in wedge-shaped vertebrae (Fig. 13). The pelvis is slightly deformed and compressed. The long bones are slender, and the cortex thin, but on the whole the skeletal ossification is much more substantial than in the other two cases. Multiple fractures are present, either united or in a stage of uniting. The right humerus is plated where there had been a recent recurrent fracture (Fig. 14).

\section{Summary}

Osteogenesis imperfecta is reviewed and a classification according to the radiological findings in the various age groups is given, together with a description and radiographs of three typical cases of osteogenesis imperfecta.

We wish to extend our thanks to Miss Campbell for the radiographs and to Mr. Theo Marais for the photographic reproductions of the radiographs and the other photographs of the patients, and to Dr. L. Pannall for particulars of E.S.

\section{REFERENCES}

Bauer, K. H. (1920). Dtsch. Z. Chir., 160, 289.

Bickel, W. H., Ghormley R. K. and Camp, J. D. (1943). Radiology, 40, 145.

Biering, A. and Iversen, T. (1955). Acta paediat. (Uppsala), 44, 279. Brailsford, J. F. (1943). Brit. J. Radiol., 16, 129.

(1953). The Radiology of Bomes and Joints, p. 605. 5th ed.

London.
Fairbank, T. (1951). An Atlas of General Affections of the Skeleton, p. 1. Edinburgh.

Follis, R. H. (1952). J. Pediat., 41, 713.

Knaggs, R. L. (1924). Brit. J. Surg., II, 737. Luck, J. Vernon. (1950). Bome and Joint Diseases, p. 382. Spring-

Shanks, S. C. and Kerky, P. (1950). A Text-book of X-ray Diagnosis by British Authors. 2nd ed. Vol. 4. London.

Vrolik, W. (1849). Tabulae ad illustrandam embryogenes in hominis et mammalium. tam naturalem quam abnormem, Tab. 91 . Amsterdam. 